Review

\title{
Potential of Genomic Selection and Integrating “Omics” Data for Disease Evaluation in Wheat
}

\author{
Jemanesh K. Haile ${ }^{1, *}$, Amidou N'Diaye ${ }^{1}$, Ehsan Sari ${ }^{1}$, Sean Walkowiak ${ }^{2}$, \\ Jessica E. Rutkoski ${ }^{3}$, Hadley R. Kutcher ${ }^{1}$, Curtis J. Pozniak ${ }^{1, *}$ \\ 1 Crop Development Centre, Department of Plant Sciences, University of \\ Saskatchewan, Saskatoon, SK S7N 5A8, Canada \\ 2 Grain Research Laboratory, Canadian Grain Commission, Winnipeg, MB R3C \\ 3G8, Canada \\ 3 Department of Crop Sciences, University of Illinois at Urbana-Champaign, \\ Urbana, IL 61801, USA \\ * Correspondence: Jemanesh K. Haile, Email: jemanesh.haile@usask.ca; \\ Tel.: +1-306-966-2430; Curtis J. Pozniak, Email: curtis.pozniak@usask.ca; \\ Tel.: +1-306-966-2361.
}

\begin{abstract}
Diseases are among the most important limiting factors for wheat production. Breeding for fungal diseases of wheat, primarily for rusts and Fusarium head blight (FHB), are major resource consuming activities in most breeding programs which prevent breeders from focusing entirely on improving yield. Breeding for these diseases is challenging because resistance is inherited mostly in a quantitative fashion and is greatly influenced by weather conditions. Recent advances in genomics, phenomics and big-data analysis provide opportunities for accelerating the development of low-cost and efficient selection methods for such complex traits. Genomic selection (GS) may provide opportunities for reducing the time and cost of making selections. By appropriately integrating GS in the breeding workflow, it is possible to select new parents purely based on genomic estimated breeding values before breeding materials are entered into nurseries and field trials. Due to reduced selection cycle time, annual genetic gain for GS is predicted to be two to threefold greater than for a conventional phenotypic selection program. In this paper, we review the recent GS studies focusing on the prediction of resistance to rusts and FHB including those that benefits from modeling multiple phenological traits correlated with the resistance. In addition, we discuss the potential of integrating phenomics and machine learning for evaluating plant disease and the integration of multiple "omics" data in genomic prediction to improve the applicability of GS for disease resistance breeding in wheat.
\end{abstract}

\section{G Open Access}

Received: 27 May 2020 Accepted: 12 October 2020 Published: 27 October 2020

Copyright $(2020$ by the author(s). Licensee Hapres, London, United Kingdom. This is an open access article distributed under the terms and conditions of Creative Commons Attribution 4.0 International License.
KEYWORDS: disease resistance; genomic selection; genetic gain; genotyping; machine learning; "omics” data; phenomics; wheat 


\section{INTRODUCTION}

There is a growing need to invest in crop improvement to ensure food security for the future, which is challenged by an ever-increasing global population, climate change, extreme weather phenomena and the unsustainable use of natural resources. Based on the United Nations projection, the global human population would be 9.7 billion by 2050, 10.8 billion by 2080, and 11.2 billion by 2100 [1]. Plant breeders and scientists are under pressure to improve crops to be higher yielding, more nutritious, pest- and disease-resistant and climate-smart [2]. A shift in global temperatures and other climatic conditions will results in various changes in wheat diseases, including pathogen populations, which will mean that breeders will need to continuously adapt crops to combat these diseases [3].

Wheat is one of the most important cereals in the world and plays a vital role in addressing food security [4]. Diseases are among the most important limiting factors that affect wheat production. There are a number of wheat diseases and insects that cause significant crop loss and result in an increased input costs for farmers. Three rust pathogens: Puccinia triticina (leaf rust), Puccinia striiformis f. sp. tritici (stripe rust), and Puccinia graminis f. sp. tritici (stem rust) are among the most damaging pathogens and have caused massive losses to wheat production in some areas [5-11]. Each of these pathogens can cause yield losses of up to $50 \%$ or more during severe epidemics and when environmental conditions are favorable [12,13]. Fusarium spp. that cause Fusarium head blight (FHB) in wheat are also challenging pathogens for wheat production, as they penalize both grain yield and quality, and contaminate grains with mycotoxins such as trichothecene deoxynivalenol (DON) [14].

\section{Importance of Rust and FHB Resistance}

Improving disease resistance in wheat is very important as it also improves yield, quality and even some agronomic traits. Rust pathogens have hindered global wheat production since the domestication of the crop and continue to threaten the world's wheat supply [15]. Leaf rust is a problematic disease because the pathogen displays high diversity; there is a constant emergence of new races and the pathogen exhibits high adaptability to a wide range of climates $[9,16,17]$. Similarly, in recent years, stem rust has re-emerged as a concern as new physiological races have evolved in Puccinia graminis f. sp. tritici population, demonstrating the vulnerability of broadly grown wheat cultivars with limited number of major rust resistance genes across the globe [18-20]. Stem rust has the capacity to destroy millions of hectares of healthy, high-yielding wheat in less than a month by reducing fields to a mass of bare, broken stalks supporting only small, shriveled grains by harvest time [21]. In addition, fungicide treatment against stem rust is very hard to apply because it would require farmers to drive through their fields after flowering has 
occurred with potential damage to their yields. Stripe rust, also known as yellow rust, occurs around the world in environments where growingseason conditions are humid and cool or at high altitude areas with warm day and cooler night temperatures [5]. However, strains of stripe rust have recently developed with a broader range of temperature adaptation [22]. The pathogen is highly variable, affecting the durability of resistance.

Breeding resistant cultivars is an important component of an integrated FHB management strategy. Resistance to FHB is quantitative, requiring a quantitative approach for evaluation and analysis. Genetic studies conducted over the last decade have identified over 500 FHB resistance QTL on all wheat chromosomes [23-25]. Fhb1, on chromosome 3B is the most consistently reported QTL for FHB resistance breeding from Chinese wheat cultivar Sumai 3. The resistance genes within the Fnb1 have been cloned [26,27]. Fhb1 has provided by far the strongest level of disease severity reduction ranging between $20 \%$ and $25 \%$ [28]. Low frequency of resistance alleles in elite wheat breeding parents and concerns about the detrimental effect of linkage drag has limited the utilization of Fhb1 in breeding programs [29,30]. Recently another FHB resistance gene transferred from Thinopyrum to wheat, $F h b 7$, has been cloned and its resistance mechanisms has been characterized [27]. Fhb7 resistance differs from Fhb1 resistance, which depends on a reduction of pathogen growth in spikes, although both confer durable resistance [27]. The ability of $F h b 7$ to detoxify multiple mycotoxins produced by various Fusarium species demonstrates its potential as a source of resistance to the various diseases for which Fusarium trichothecenes are virulence factors [27]. A previous study proposed an additive effect of FHB resistance QTL [31], implicating the feasibility of improving FHB resistance by combining minor effect QTL. Phenotyping over multiple environments is routinely conducted to identify superior FHB resistant germplasm. Phenotypic selection has been successful in spite of interactions between FHB resistance loci and the environment, and the unfavorable association of FHB resistance with agronomic traits such as plant height ( $\mathrm{PH})$ and maturity [32-35].

\section{Selection for Resistance to Rust and FHB}

Selection for resistance to rust and FHB in wheat is resource demanding and diverts breeding resources away from other priority traits, including yield. Each breeder needs to make the strategic decision of which disease resistance to target, keeping in mind that each additional trait will ultimately reduce the selection intensity (i.e., the chances of success) for other traits, when assuming fixed population size or limited budget [36]. Currently, phenotyping rusts and FHB requires observation of visible symptoms and screening of hundreds or thousands of lines to identify resistant plants, which is a costly and labor intensive process. The time constraints are also prohibitive if the window of opportunity for phenotyping is narrow. Moreover, conventional phenotyping approaches 
tend to have high experimental errors due to inaccurate or subjective visual assessments.

Rusts and FHB are challenging diseases to improve because resistance is inherited in a quantitative fashion and is greatly influenced by environmental conditions. Current advances in genomics and bioinformatics provide opportunities for accelerating the development of efficient and low-cost genomic selection methods for such complex traits [37-39]. In addition, developing high-throuput phenotyping techniques combined with the power of machine learning (ML) would improve the efficiency of disease assessment in field and is integral to the sucess of GS.

\section{Genomic Selection}

Genomic selection has been considered one of the key post1990 technologies utilized in plant improvement, along with transgenic cultivars, QTL mapping, association mapping, phenomics, envirotyping, genome editing, sequencing, and doubled haploid production [40,41]. In GS, a training population is genotyped with genome-wide markers and phenotyped for the trait under selection. GS models are then trained with the marker and phenotype data, and the model is used to predict the breeding value of new set of individuals (selection candidates) that have been genotyped but have not been phenotyped. Unlike traditional marke $r$ assisted selection (MAS), which uses a small number of markers associated with major QTL, GS uses genome-wide markers with phenotyping data to calculate (GEBVs) in one population that will predict the performance of lines in another population only using markers [42]. This avoids multiple testing and the need to identify marker-trait associations based on an arbitrarily chosen significance threshold. Studies indicate that GS outperforms traditional marker-assisted selection for complex traits controlled by many minor effect QTL with low heritability [43-47]. If adequately integrated into the breeding workflow GS can partially replace field testing and therefore reduces line development time [46].

Genomic selection has been well established in the field of animal breeding, but many plant breeding programs worldwide are still evaluating the optimal strategy and stage for implementation in a breeding program. Wheat breeding programs typically require 10-15 years to transfer novel genes into elite germplasm. By application of GS, it is possible to select new parents purely based on GEBV before being entered in field trials and nurseries [48-50]. Because of reduced selection cycle time, annual genetic gain for GS is predicted to be two to threefold greater than for a conventional phenotypic selection program [46,51-58]. However, there is still limited information on the application of GS for improving disease resistance in wheat.

The earliest review by Rutkoski et al. [59] addressed the implementation of GS for adult plant stem rust resistance in wheat and 
later Poland and Rutkoski [60] reviewed GS studies for diseases resistance published until 2015. Thus, in this review, we discuss the recent methods and studies reported between 2016 and 2020 about (a) GS for resistance to rusts and FHB, (b) GS for multiple correlated traits, which may be useful for breeding for disease resistance, (c) the application of phenomics and ML to evaluate plant disease, and (d) advances in genotyping and the application of other "omics" technologies in GS to predict disease resistance in wheat.

\section{GENOMIC SELECTION FOR DISEASE RESISTANCE}

Resistance to wheat rusts generally falls into two categories: (i) all stage resistance, which is often conferred by race-specific resistance genes ( $R$ genes) involved in pathogen recognition and associated with a hypersensitive response, and (ii) slow rusting adult plant resistance (APR), which is quantitative resistance often conferred by multiple loci, and is not associated with a hypersensitive response. $\mathrm{R}$ genes protect the plant from seedling to adult growth stages whereas APR genes function mainly at the adult stage [61]. Quantitative disease resistance is more durable than qualitative resistance conferred by R genes [59,62,63]. Phenotyping APR in large populations is expensive and labor intensive, as it requires conducting both seedling and adult plant screening. Resistance to FHB in wheat is inherited quantitatively and strongly influenced by the environment [23]. In general, breeding for quantitative disease resistance is a challenge because of the low heritability and high genotype $\times$ environment interaction, emphasizing the importance of devising strategies for more effective evaluation and exploitation of this resistance [64].

Marker assisted selection is useful for major effect QTL, but for FHB and rust resistance the individual QTL often have small effects. Additionally, only a few monogenic rust resistances are durable and only a few rust and FHB QTL with large effects have been successfully transferred into elite breeding material [36]. Further constraints like lack of diagnostic markers and the prevalence of QTL-background effects hinder the broad implementation of MAS [36]. GS is a promising approach that can potentially accelerate breeding for quantitative resistance by providing accurate predictions of resistance levels, reducing time to parental selection and increasing genetic gain from selection. GS will also open new avenues for molecular based resistance breeding by capturing more of the variation due to small effect QTL $[39,58,65]$. This makes GS well suited for rust and FHB resistance breeding. To achieve even greater gains, multiple traits can be simultaneously targeted for GS [2] including morphological traits correlated with disease resistance. Selection strategies which combine disease resistance with other traits offer efficient use of resources by assaying multiple traits on the same set of plants. 


\section{Strategies for Improving GS Prediction Accuracy}

Several different strategies have been tested and reported to increase GS prediction accuracies. Some of them are: combining pedigrees and markers [66], applying GS models that account for interactions between genotype and environment [67], incorporating additional secondary traits [56], and incorporating additional genomic and/or biological information, such as that revealed in a genome wide association study (GWAS), into the GS model [68], termed GS + de novo GWAS. Combining pedigree with markers for prediction has been shown to improve accuracy compared to prediction based on either pedigree or the markers alone. Juliana et al. [64] found that combining marker and pedigree-based relationship matrices lead to the highest GS accuracies for APR for all three rusts of wheat. In the GS + de novo GWAS approach, significant markers identified by GWAS were included as fixed effects in the GS model and removed from the matrix of random effects. Besides enhancing prediction accuracy, GS + GWAS does not require additional data because the same phenotypic and genotypic data set is used, and it can be more accessible to breeders as it does not require extensive knowledge of the underlying genetics of a trait of interest [68]. The benefits of integrating GWAS with GS to further improve the accuracy of GS in wheat are confirmed for rusts [69,70], Septoria tritici blotch [71,72], and yield [73]. Particularly, Daetwyler et al. [69] and Rutkoski et al. [70] demonstrated the advantage of including markers linked to large to moderate effect genes or loci previously found to affect the traits of interest. On the other hand, according to Arruda et al. [74], treating random SNPs as fixed effects, reduced prediction accuracy.

Another strategy is the application of GS on landraces stored in genebanks to obtain GEBVs for economically important traits by training models on a subset of phenotyped landraces [75]. Muleta et al. [76] have also shown the feasibility of this approach by using empirical data collected for adult plant resistance to stripe rust from 1163 spring wheat accessions and suggested that genomic prediction can provide a promising global strategy for mining useful alleles from crop germplasm collections. In addition, the results of this study showed promising prediction accuracies for potential use in germplasm enhancement and rapid introgression of exotic germplasm into elite materials. The application of GS for selected bulk and recurrent selection methods and backcrossing as possible breeding schemes to enhance rust resistance of wheat is well explained [59]. Despite the availability of a large number of wheat wild relatives and landraces in genebanks, their utilization has been impeded largely due to limited phenotyping data. GS can significantly contribute to mobilizing the genetic variation within the non-adapted germplasm through accurate predicting of FHB and rust resistance phenotype.

As durable resistance needs the effective combinations of major and minor genes [77,78], the integration of MAS and GS for selection of both is reasonable for enhancing disease resistance germplasm. Cerrudo et al. [44] proposed the use of QTL based MAS for forward breeding to enrich 
the allelic frequency of traits with large additive effect QTL in early selection cycles, while GS could be used in more advanced breeding cycles to capture additional alleles with smaller additive effects. Extensive deployment of large-effect rust resistance genes/QTL in resistant cultivars imposes strong selection pressure [79], on the pathogen population which can lead to pathogen virulence shifts or mutations [80]. Enhancing quantitative rust resistance in wheat using GS is hence highly desired.

\section{Genomic Selection for Rust Resistance in Wheat}

The potential for increased genetic gain for rust resistance in wheat through GS has been recognized [56,64,69,70,76,78,81]. There is still limited information on the application of GS to exploit disease resistance from exotic or uncharacterized germplasm from gene banks, however, most GS studies have been based on bi-parental and multi-family breeding populations.

Among the few studies that have shown the feasibility of GS to predict rust resistance in wheat, Juliana et al. [64] achieved mean genomic prediction accuracies ranging from $0.12-0.56$ for leaf rust (LR), 0.31-0.65 for stem rust (SR), and 0.34-0.71 for stripe rust (YR). They examined adult plant resistance in a population of 333 and 314 advanced lines from the Centro Internacional de Mejoramiento de Maíz y Trigo (CIMMYT) wheat breeding program. Their results indicated that using genome-wide marker-based models resulted in an average of a $42 \%$ increase in accuracy over the least-squares approach, which involves an initial marker ranking and selection step. This indicated that GS was a promising approach for improvement of quantitative rust resistance in the breeding pipeline.

Using a set of 365 advanced CIMMYT wheat data for quantitative APR to SR, Rutkoski et al. [81] indicate how historical data could be used to successfully initiate a GS program for resistance breeding. They used a second population of 503 new selection candidates (SCs) which was generated by two rounds of random mating between 14 founder lines from the historical population, followed by one round of selfing for seed increase. They have evaluated these individuals for quantitative APR to stem rust and genotyped using genotyping-by-sequencing approaches and analyzed using GBLUP. A training population taken from SCs and formed from historical population was compared by taking a subset of lines from SCs as a validation population. Their results showed that lower accuracy was obtained when retaining historical data especially when the heritability of the historical data was low, the heritability of the close relative training data was high, and the observations were not weighted properly according to heritability. This has implications for prediction model updating. In a selection program, it may be better to discard historical data and simply use the most recent data for model training. However, when to discard training data will need to be determined empirically because it will depend on the selection intensity of the 
breeding program, the availability of data on close relatives, and quality of the historical data [81].

Muleta et al. [76] used empirical data for APR to YR collected on 1163 spring wheat accessions and genotypic data based on the wheat 9K Single nucleotide polymorphism (SNP) iSelect assay to estimate GEBVs for stripe rust resistance under scenarios of different population sizes, degrees of genetic relatedness within a population, and marker densities from multienvironment field trials. According to their results, larger germplasm collections may be efficiently sampled via lower-density genotyping methods, whereas genetic relationships between the training and validation populations remain critical when exploiting GS to select for resistance to YR from germplasm collections. In addition, this study revealed that GS could provide an efficient and cost-effective sampling strategy of unlocking the potential of wheat genetic resources and accelerating the rate of genetic gain in wheat breeding programs. Examples of GS studies reported for SR, YR and LR resistance in wheat after 2015 including information on the training and test population, the GS models used, and the accuracy of the prediction is presented in Table 1.

Table 1. Examples of GS studies of rust resistance in wheat.

\begin{tabular}{|c|c|c|c|c|c|c|}
\hline Plant materials & $\begin{array}{l}\text { Population } \\
\text { size }\end{array}$ & $\begin{array}{l}\text { Rust } \\
\text { evaluation }\end{array}$ & Model & $\begin{array}{l}\text { Maximum } \\
\text { prediction } \\
\text { accuracy }\end{array}$ & $\begin{array}{l}\text { Within (W) } \\
\text { vs across } \\
\text { (A)-cycle } \\
\text { prediction }\end{array}$ & Reference \\
\hline Historical bread wheat & 365 & $\mathrm{SR}^{1}(\mathrm{APR})$ & GBLUP $^{6}$ & 0.45 & $\mathrm{~W}$ & [81] \\
\hline population & & & & 0.30 & A & \\
\hline Hexaploid spring & 1163 & $\mathrm{YR}^{2}\left(\mathrm{IT}^{4}\right)$ & $\operatorname{rrBLUP}^{7}$ & 0.65 & A & {$[76]$} \\
\hline \multirow[t]{2}{*}{ wheat accessions } & & YR (severity) & & 0.63 & A & \\
\hline & & YR (IT) & & 0.80 & $\mathrm{~W}$ & \\
\hline International bread & 333 & $\mathrm{LR}^{3}$ (seedling) & RKHS-MP ${ }^{8}$ & 0.74 & $\mathrm{~W}$ & {$[64]$} \\
\hline \multirow[t]{3}{*}{ wheat nursery } & & $\mathrm{LR}\left(\mathrm{APR}^{5}\right)$ & RKHS-MP & 0.52 & $\mathrm{~W}$ & \\
\hline & & YR (APR) & GBLUP A $^{9}$ & 0.70 & $\mathrm{~W}$ & \\
\hline & & SR (APR) & RKHS-MP & 0.65 & $\mathrm{~W}$ & \\
\hline International bread & 313 & LR (seedling) & GBLUP A & 0.70 & $\mathrm{~W}$ & [64] \\
\hline \multirow[t]{4}{*}{ wheat nursery } & & YR (seedling) & GBLUP A & 0.78 & $\mathrm{~W}$ & \\
\hline & & LR (APR) & RKHS-MP & 0.56 & $\mathrm{~W}$ & \\
\hline & & YR (APR) & GBLUP A & 0.71 & $\mathrm{~W}$ & \\
\hline & & SR (APR) & RKHS-MP & 0.62 & $\mathrm{~W}$ & \\
\hline
\end{tabular}

${ }^{1}$ Stem rust; ${ }^{2}$ yellow rust; ${ }^{3}$ leaf rust; ${ }^{4}$ infection type; ${ }^{5}$ adult plant resistance; ${ }^{6}$ genomic best linear unbiased prediction; ${ }^{7}$ ridge regression best linear unbiased prediction; ${ }^{8}$ reproducing kernel Hilbert spaces with marker and pedigree relationship matrices; ${ }^{9}$ GBLUP with selected loci as fixed effects.

\section{Genomic Selection for FHB Resistance in Wheat}

Phenotyping for FHB is laborious and expensive, requiring the preparation of large amounts of inoculum and establishing mist irrigation 
in additional to general crop management practices. Phenotyping for mycotoxin is only conducted after harvest; is expensive and labor intensive, and weakly correlated with visual assessments of FHB resistance [82]. Considering these complexities, developing reliable markers for marker-assisted selection (MAS) is highly desirable. However, the implementation of MAS for FHB is deemed only partially effective due to the complex genetic architecture [83]. GS models can enhance selection capacity at early breeding cycles when FHB phenotyping is impractical due to the large population size and low number of seeds. The application of GS allows the effective utilization of limited FHB nursery capacity for evaluating the most promising breeding materials, hence accelerating the release of resistant cultivars.

Most GS studies of FHB resistance used ridge regression-best unbiased linear prediction (rrBLUP). This is an infinitesimal model with all markers sharing a common variance, and all effects are shrunken toward zero [84]. When major genes are present, this model underestimates the genetic variance. Alternative models that account for the effect of major genes are Bayesian [85], least absolute shrinkage and selection operator (LASSO) [86] and the elastic net [87] that combines LASSO and rrBLUP strengths in a single model. Both Bayesian and LASSO model were previously used for GS of FHB by Rutkoski et al. [88] however, none of them provided higher prediction accuracy over rrBLUP. Arruda et al. [48] suggested that rrBLUP outperform LASSO and elastic net in a GS study of FHB in a population consisting of soft red winter wheat lines from midwestern and eastern United States. Multiple studies also used genomic best linear unbiased prediction (GBLUP) which uses genomic relationship to estimate phenotype and is the most basic GS model [89]. GBLUP has been successfully used by three independent GS studies of FHB since 2016 [83,90,91] (Table 2). Given the contribution of several minor effect genes to FHB resistance, rrBLUP is therefore the most common model advised for GS of FHB, and other models that consider marker effects such as LASSO and Bayesian are less common. An additional drawback of LASSO and Bayesian models is that they are very computationally demanding [74].

An alternative approach that is often used to improve rrBLUP prediction is to identify FHB resistance QTL using GWAS and treat them as fixed effects in the model. For example, Arruda et al. [74] reported up to $15 \%$ improvement in prediction accuracy after combining the FHB resistance QTL into the rrBLUP model as fixed effects. For the training population, it seems beneficial to conduct a GWAS to identify QTL and combine them into rrBLUP model as fixed effect. However, this may introduce an artifact if the entire population, including the training and validation set, is used to identify QTL. In a realistic scenario, the validation set does not have phenotypic data and cannot be used for QTL detection. Using data from the validation set to help improve prediction accuracy is an example of "data snooping". In certain cases, the data snooping can 
make MAS appear more effective than GS as suggested for some FHB traits measured in 273 soft red winter wheat lines from the US Midwestern and Eastern regions [74].

Several studies have shown that phenotypic selection is more accurate than GS [91,92]. However, according to Steiner et al. [91], the application of GS for FHB resistance led to a 43\% selection advantage over a two-stage FHB phenotypic selection. Since GS across cycles (predicting using phenotypic data obtained from previous breeding cycles) generally has a lower prediction accuracy than the within cycle GS, such application in breeding programs requires the improvement of GS across cycles. The increasing application of GS for yield in wheat breeding programs, along with the availability of skim sequencing at reasonable prices indirectly provide the opportunity to use GS for FHB resistance at nearly zero cost. This reserves the limited capacity in FHB nurseries for testing more advanced elite materials and hence accelerates the release of FHB resistant cultivars. Awareness of the relatedness between training and validation populations and periodic updating of the selection models are imperative for the reliable application of GS in wheat breeding programs. GS studies addressed in this review are summarized in Table 2.

\section{Genomic Selection for Correlated Disease Resistance Traits}

The undesirable association between agronomic traits such as plant height $(\mathrm{PH})$ and heading date (HD) with FHB resistance is a challenge for the application of GS. There is compelling evidence supporting the negative correlation between FHB resistance and $\mathrm{PH}$ and HD, which is often reflected as the co-localization of $\mathrm{PH}$ and HD QTL with FHB resistance QTL [32,34,35,93]. The dwarfing alleles of $R h t-B 1$ and $R h t-D 1$ have been associated with FHB susceptibility [94,95]. This has motivated the phenotyping of PH and HD along with FHB resistance for most GS-FHB studies conducted since 2016 (Table 2). Interestingly, PH and HD were integrated into the GS models differently. Moreno-Amores et al. [83] evaluated three different approaches to combine PH and HD in the GS model: (1) correcting the FHB resistance trait values using $\mathrm{PH}$ and $\mathrm{HD}$ followed by using the corrected phenotypic data for single-trait GS (STGS), (2) using PH and HD for Multi-Trait GS (MTGS), and (3) adjusting GS using restriction indices with variable restriction enforced for FHB resistance, $\mathrm{PH}$ and HD. They indicated that combining $\mathrm{PH}$ and $\mathrm{HD}$ as a fixed effect in the GS model is a reasonable strategy to select moderately resistant lines with lower PH and earlier HD than the population average. In other words, successful selection is attainable to fine tuning the tradeoff between prediction accuracy and acceptable reduction in unfavorable agronomic traits. Steiner et al. [91] also reported marginal improvement when using a MTGS model that combined PH and flowering date (FD), although it largely inflated the negative trade-off between GEBVs for FHB severity and the undesirable agronomic traits. They then applied a restriction index to 
Table 2. Examples of GS studies of FHB in wheat.

\begin{tabular}{|c|c|c|c|c|c|c|c|}
\hline Plant materials & $\begin{array}{l}\text { Population } \\
\text { size }\end{array}$ & $\begin{array}{l}\text { FHB and agronomic } \\
\text { traits }\end{array}$ & Model & Treatment of covariance & $\begin{array}{l}\text { Maximum } \\
\text { prediction } \\
\text { accuracy }\end{array}$ & $\begin{array}{l}\text { Within (W) } \\
\text { vs across } \\
\text { (A)-cycle } \\
\text { prediction } \\
\end{array}$ & Reference \\
\hline Soft red winter wheat & 273 & $\begin{array}{l}\text { FHB inc, FHB sev, } \\
\text { FHB index }^{7}, \mathrm{FDK}^{8}, \\
\text { ISK }^{9}, \text { DON }\end{array}$ & rrBLUP & NA & 0.9 & $\mathrm{~W}$ & [74] \\
\hline $\begin{array}{l}\text { Durum diversity mostly winter } \\
\text { type }\end{array}$ & 178 & FHB sev ${ }^{1}, \mathrm{PH}^{2}, \mathrm{HD}^{3}$ & GBLUP ${ }^{10}$ & PH and HD as fixed effect & 0.75 & $\mathrm{~W}$ & [83] \\
\hline Spring wheat hybrids & 1604 & FHB sev, PH, HD & GBLUP & Multi-trait prediction & 0.8 & $\mathrm{~W}$ & [90] \\
\hline Durum wheat cultivars & 228 & FHB sev, PH, FD ${ }^{4}$ & GBLUP & Multi-trait prediction & 0.6 & A & {$[91]$} \\
\hline $\begin{array}{l}\text { Durum wheat diversity mostly } \\
\text { winter type }\end{array}$ & 184 & FHB sev, PH, HD & rrBLUP & NA & 0.7 & $\mathrm{~W}$ & [92] \\
\hline $\begin{array}{l}\text { Winter wheat breeding lines } \\
\text { from } 14 \text { bi-parental population }\end{array}$ & 1120 & FHB sev, PH, HD & Weighted rrBLUP ${ }^{11}$ & Not included & 0.72 & $\mathrm{~W}$ & [96] \\
\hline Spring wheat breeding lines & 439 & FHB sev & rrBLUP & NA & 0.42 & $\mathrm{~A}$ & [97] \\
\hline Spring wheat breeding lines & 170 & $\begin{array}{l}\text { FHB Inc }{ }^{5}, \text { FHB Sev } \\
\text { and DON }\end{array}$ & rrBLUP & NA & 0.6 & $\mathrm{~W}$ & [98] \\
\hline
\end{tabular}

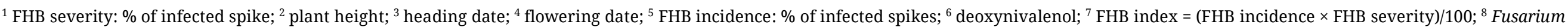
damaged kernel; ${ }^{9}$ incidence-severity-kernel index $=0.3 \mathrm{FHB}$ inc $\times 0.3 \mathrm{FHB}$ sev $\times 0.4 \mathrm{FDK} ;{ }^{10}$ genomic best linear unbiased prediction; ${ }^{11}$ ridge regression-best unbiased linear prediction. 
compensate for inflation that only led to marginal improvement. These results reiterate the trade-off between integrating $\mathrm{PH}$ and $\mathrm{FD}$ in the multivariate model and the reduction in prediction accuracy of FHB resistance. Comparing STGS and MTGS for FHB resistance in a population of 1604 wheat hybrids, Schulthess et al. [90] suggested that the application of MTGS is only advantageous for genotypes less related to the training set. They also proposed the concept of "phenotype imputation", when the indirect selection of a highly heritable traits leads to improvement in a correlated trait of lower heritability [53,99]. By progressively reducing the intensity of FHB resistance phenotyping and thus trait heritability, they proved that FHB severity could be imputed from $\mathrm{PH}$ data. To alleviate the unfavorable increase in $\mathrm{PH}$, a tandem selection strategy or a restricted selection index that discards the extremely tall plants prior to GS was recommended [90]. The low variation for FHB resistance in short and early flowering lines and the pleiotropic effects of $\mathrm{PH}$ and HD genes on FHB resistance are some of the impediments to the use of MTGS for GS of FHB resistance.

Given the unfavorable association of FHB resistance with $\mathrm{PH}$ and HD, genomic prediction indices are expected to minimize the bias for the undesirable traits and thus allow GS of FHB resistance, semi-dwarf and early-heading lines. Steiner et al. [91] deployed a GS index by assigning different weight to FHB resistance, PH and FD. Genomic selection of only FHB traits in the model resulted in an undesirable increase in PH and FD, which could be compensated for by the application of the selection index. The resulting reduction in prediction accuracy was mitigated by adjusting the weight of each trait in the selection index. The integration of FHB resistance QTL as fixed effect in the STGS along with MTGS guided by restriction indices are thus far the most promising strategies for the GS of FHB resistance.

Incorporation of multiple traits into GS models for FHB shows promise; this is particularly true in the advent of high-throughput phenotyping and phenomics. Application of phenomics in plant breeding has recently gained attention. It also enables the discovery of agronomic traits with FHB resistance that have not yet been examined. Enhancing highthroughput phenotyping for FHB resistance under field conditions is expected to increase the accuracy and reduce the cost of phenotyping. Significant progress has been made in developing algorithms capable of accurate detection of wheat spikes from images collected using Ground Mobil imaging units [100]. This will pave the way for the detection of infected areas of spikes using deep learning techniques in future [100]. Improving the phenotyping accuracy and throughput can improve the predictability of GS models over the levels predicted in the previous studies. In addition to providing FHB phenotyping data, information on other traits is also collected through analysing high-resolution images captured by Mobil imaging units and/or Unmanned Aerial Vehicle with 
minimal effort. These additional data can be incorporated into multi-trait GS models to improve prediction accuracies for FHB resistance.

\section{APPLICATIONS OF PHENOMICS AND MACHINE LEARNING FOR EVALUATING PLANT DISEASE}

Plant breeders are constantly searching for specific traits that help farmers grow crops more efficiently, while using fewer natural resources. They usually phenotype large populations for several traits throughout the crop growth cycle. This tedious task of phenotyping multiple traits and large populations is exacerbated by the necessity of sampling multiple environments and growing replicated trials.

New technologies and tools have emerged to speed up the breeding process for rapid release of cultivars that meet the industry and consumers demands. An example of this is high-throughput phenotyping and imaging, which enables non-destructive field-based plant phenotyping for a large number of traits including physiological, biotic (e.g., weeds, insects and diseases caused by fungi, bacteria and virus) and abiotic (e.g., heat, drought, and flood, nutrient deficiency) stress traits [101,102]. The adoption of new phenotyping and genotyping technnolgies has generated a huge amount of complex data, including sequencing data, transcriptomic data, metabolomics data and imaging data. A challenge attached to the exponential growth of data is analysis and interpretation. Machine learning (ML) is set to play a pivotal role in sustainable and precision agriculture. One of the major advantages of ML is the ability to search large datasets to discover patterns and features (traits) by simultaneously looking at a combination of factors instead of analyzing each feature individually. Because ML algorithms can potentially approximate any function, ML may easily uncover genuine patterns within complex datasets [103,104]. In addition, ML allows algorithms to interpret data by learning patterns through experience [105].

Success stories of ML cover various research fields, including robotics [106], bioinformatics [107], biochemistry [108], medical diagnosis [109,110], meteorology [111] and climatology [112]. In agricultural research, ML techniques have been used for predicting regulatory and non-regulatory regions in the maize genome [113], predicting mRNA expression levels in maize [114], polyadenylation site prediction in Arabidopsis thaliana [115] and predicting macronutrient deficiencies in tomato [116]. Only few practical examples related to crop breeding were reported_for predicting yield in many crops (see [117] for a review), including wheat $[118,119]$ and maize [120]. ML has been also applied to FHB and rust resistance in wheat [100,121,122].

When tracking any plant disease, an early and accurate identification is essential. The traditional method of identifying disease is visual examination, which is prone to human errors and variability in scoring. For a trained algorigthm, diagnosing plant disease is essentially pattern 
recognition. After going through hundreds of thousands of diseased plant images, ML algorithms can assess disease type and severity. Deep learning techniques, particularly Convolutional Neural Networks (CNN), are quickly becoming the preferred method for automatic plant disease recognition [123]. An exhaustive study including 79 diseases (e.g., powdery mildew and leaf rust) affecting 14 plant species (e.g., soybean, corn and wheat) has confirmed the effectiveness of $\mathrm{CNN}$ for plant disease assessment [124]. Similarly, Ferentinos [125] identified plant disease through images of 25 plant species, with an average accuracy of $99 \%$ using CNN. In wheat, deep learning techniques have recently been applied to the detection of FHB with an average accuray of 92\% [100,121]. For the first study by Qiu et al. [100], field trials were divided into 10 regions of China, with a hyperspectral image acquired for each region. Several environmental factors influencing the hyperspectral imagery were considered, including wind, humidity, temperature and experimental time (noon) where the sunbeam angle was optimal. The images data were used to train nine ML algorithms. For the second study by Jin et al. [121], three wheat lines with different levels of susceptibility to FHB were cultivated on the St. Paul campus at the University of Minnesota (USA). After innocultion, data acquisition was performed with a camera imaging pipeline at the milk stage of development. Diseased areas of individual spikes were detected using a deep convolutional neural network.

Machine learning methods are useful to analyse large data sets that are hampered by issues such as a small number of observations and a large number of predictive variables, high dimensionality or highly correlated data structures [126]. Therefore, developing high-throuput phenotyping techniques combined with the power of ML would improve the efficiency of FHB assessment in the field, as ML provides substantial advantages over other analytical approaches for large and diverse datasets such as those generated by photo imaging [127].

\section{ADVANCES IN GENOTYPING AND FUTURE PROSPECTS FOR GS}

Genomic selection has been established on the availably of DNA markers linked with all small effect loci contributing to phenotype. In fact, reduction in genotyping cost and the availability of high-density genotyping platform has been the driving force for the application of GS in plant breeding. Single nucleotide polymorphism (SNP) array and genotyping-by-sequencing platforms have been developed for over 25 crop species (reviewed by Rasheed et al. [128]. Although, for the majority, an ultra-high throughput and cost-effective genotyping platforms desirable for GS is still not available.

Wheat genomics came of age with the availability of bread, durum and wild emmer wheat reference genome assemblies in the past few years [124,129,130]. The genomes of 15 wheat cultivars assembled through 10+ Wheat Genomes Project is now publicly available (Walkowiak et al. under review; http://www.10wheatgenomes.com/). Leveraging these resources to 
devise high-throughput and cost-effective genotyping platforms is a significant step toward transferring these investments to breeders and consequently farmers' fields.

To date of this review, five SNP chips have been developed and benchmarked for genotyping wheat. Such efforts were initiated by developing a SNP array with 9000 gene-associated SNPs in a worldwide bread wheat collection of 2994 accessions [131] followed by development of the wheat 90K iSelect array [132] from RNA sequences of a diverse panel of 726 accessions including tetraploid and hexaploid landraces. The wheat 90K iSelect array is by far the most intensively used SNP array in wheat mapping research. High-throughput SNPs arrays for wheat have also been developed, i.e., the wheat $660 \mathrm{~K}$ axiom (https://www.cerealsdb.uk.net/ cerealgenomics/CerealsDB/axiom download.php) and the Wheat HD genotyping array [133]. The later harbor 820K SNPs and integrate variation from diploid, tetraploid and hexaploid wheat accessions and wheat relatives, thus enhancing the genotyping capacity beyond the primary gene pool [133]. Among the very few efforts to make these resources accessible to breeders is the generation of the Wheat Breeder's Genotyping Array by refocusing on 35K mostly co-dominant SNPs discovered through exome sequencing of wheat cultivars. Genotyping by SNP arrays has significantly boosted high-density linkage and QTL mapping and GWAS in wheat; however, the cost of genotyping has impeded intensive application of GS because it requires genotyping several thousand lines per year.

Genotyping through sequencing has been widely applied for de novo discovery of SNPs in model plants. Application of this approach has been slow in wheat mainly due to the absence of a high-quality reference genome and the high cost of genome sequencing [134]. The high sequencing cost of the large genome of wheat has motivated researchers to apply reduced-representation methods such as RNA-seq [135], exomesequencing [136] and genotyping-by-sequencing [137]. In certain cases, the reduced representation methods have been used to obtain the sequence of certain gene families in wheat, e.g., disease resistance genes [138]. As the cost of sequencing is reduced and SNP imputation methods improve, low coverage (skim) sequencing is gaining attention due to its lower error rates and higher genome coverage. Availability of third-generation sequencing at a reasonable cost based on long sequencing reads hold a potential for further integration of structural variants such as presence/absence variants (PAVs) and copy number variants (CNVs) into QTL mapping and genomic prediction studies. PAVs and CNVs seem to form a significant portion of the variation present between cultivars and wild germplasm. Including these types of variants would be of great value for studies aimed at enhancing genetic variation in wheat. Such an effort has been initiated through an international project dubbed 4D Wheat (Diversity, Domestication, Discovery and Delivery) that targets mobilizing genetic variation in the wheat secondary and tertiary gene pools and their 
application in de novo re-domestication of wheat (Pozniak and Cloutier, personal communication). Partnerships among 4D Wheat and companies offering third generation sequencing is expected to lead to the availability third generation skim sequencing platforms enabling cost-effective discovery of PAVs and CNVs for several genetic and GS studies. Skim sequencing of exotic materials facilitate enhancing the diversity within wheat breeding gene pool.

As haplotypes are inherited independently, but not SNPs, the required number of SNPs to cover all haplotypes is often several times lower than the number discovered through most genotyping platforms discussed above [139]. However, GS accuracy is often positively correlated with marker density, as it theoretically increases the odds of QTL lying in linkage disequilibrium (LD) with at least one marker. For example, genomic prediction accuracy improved by $10 \%$ when the number of markers increased from 92 to 1158 for a population of 374 winter wheat advanced-cycle breeding lines [140]. However, the prediction accuracy plateaus at a certain marker density, depending on the genetic diversity within the population and relatedness between the training and validation population [141]. The prediction accuracy decreases as the number of markers increases over this threshold, as the consequence of an over-fitted model [142]. In most cases, 1000-1500 SNPs have been recommended for genomic prediction studies in wheat, however, the decision over what markers to include largely depends on the diversity within the training and validation population and their relatedness. Thus, it seems realistic to develop program-specific breeder SNP chips that captures the available haplotypes at a reasonable cost. The decision on what SNPs to be included in the breeder chip could be based on the estimation of LD decay over genetic distances inferred from high-density QTL mapping studies $[34,35,143]$ or comprehensive haplotype mapping of wheat diversity panels [136,144]. Thus, in addition to high-throughput phenotyping, advances in genotyping technologies are also shaping the future of GS including SNP arrays and DNA/RNA sequencing.

\section{APPLICATION OF OTHER “OMICS” IN GS}

To our knowledge other "omics" have not yet been utilized for GS in wheat. Inclusion of intermediary biological strata in the cascade from genotype to phenotype (endophenotypes) could improve prediction accuracy. This is attributed to the contribution of endophenotypes to the identification of epistatic interactions within and between various gene regulation strata [145]. The most attention has been given to the transcriptome, which reflects and quantifies gene expression. Previously, transcriptomics has been deployed for genomic prediction in maize [146,147]. The metabolome has also garnered attention since it integrates all gene regulation and interaction processes. Metabolomics has been successfully used for phenotypic prediction in maize [147]. In a recent study, the combination of transcriptomics of mRNA and sRNA, and 
metabolomic data were used to predict the yield performance of maize hybrids [145]. The combination of genomic and mRNA data returned 10\% higher prediction accuracy, while including sRNA in the model had negligible effect on the prediction accuracy. Interestingly, the difference between transcriptomic and combined genomic and transcriptomic data was negligible, suggesting that mRNA data could alone be used to achieve high predictability.

Practically, transcriptomic prediction benefits from both gene expression data and SNP discovery for a combined genomic and transcriptomic prediction platform. Despite these advantages, integration of transcriptome data has been impeded by the higher cost of mRNA sequencing compared with DNA sequencing, the poor correlation between gene expression under controlled conditions and field environments, and the tendency to discover non-heritable variation. Nevertheless, the cost seems to be reasonable in wheat hybrid breeding programs as the transcriptomes of a limited number of founder lines is analyzed. Transcriptome data could be generated for a subset of founder lines and used to develop models for imputing the value of others using pedigree and genomic data [148]. Application cost could also be reduced by utilizing 3'Pool-seq, which is claimed to reduce the library preparation cost up to $90 \%$ with marginal reduction in the accuracy of gene expression quantification [149]. In addition, the BART-seq platform allows the utilization of reduced-representation transcriptome sequencing [150] that could theoretically capture the expression of a certain set of genes relevant to the trait of interest. The validation of both methods in wheat warrants further investigation. Once validated, these techniques could be applied in future "omics" prediction studies in wheat, especially as hybrid breeding is gaining ground as a new strategy for genetic improvement in wheat [151].

\section{CONCLUDING REMARKS}

The present review tapped into several high-impact GS studies conducted during last five years for rust and FHB to identify the most effective protocol for implementing GS in breeding programs. Despite significant variability in how GS was implemented in these studies, we identified few common grounds. A significant common theme was the tendency to integrate several data e.g., pedigree, genotype $\times$ environment interaction and QTL identified through mapping studies into a model. A reasonable strategy suggested was the application of MAS to increase the frequency of favourable alleles for traits with strong additive QTL at early generations and GS to capture positive alleles with smaller additive effect in later generation materials. On the contrary, others argue the benefit of using GS at early generation where population size and shortage of seed impede intensive phenotyping at disease nurseries. The relatively low across-cycle predictability of GS is a hurdle for the application of the later strategy. The across-cycle predictability of GS could be improved by 
increasing the size of training populations, and the periodic retraining of the model and validating of the model. Accurate and high-throughput phenotyping combined with the power of ML is expected to promote the application of GS by reducing the phenotypic error and thus increasing the across-cycle predictability of GS. It could also unveil complex association of the resistance with other phenological traits and supply detailed data for modeling such complex associations.

Multi-trait GS has appeared as a useful strategy for selecting quantitative resistance, especially for FHB considering the well-realized association of FHB with PH and HD. Majority of GS studies on FHB benefit from integration of $\mathrm{PH}$ and $\mathrm{HD}$ (or FD) into the prediction models. However, unsupervised integration of $\mathrm{PH}$ and $\mathrm{HD}$ in the models leads to undesirable increase in $\mathrm{PH}$ and delayed HD. Efforts to mitigate such undesirable effects leads to reduction in the predictability of the model. Another challenge for the application of MTGS for FHB is the low variation for FHB resistance in short stature wheat germplasm and the pleiotropic effect of PH and HD on FHB resistance. Despite these challenges, MTGS was proved partially useful when GS models were adjusted using restriction indices for $\mathrm{PH}$ and $\mathrm{HD}$, allowing some selection gain for FHB resistance, semi-dwarf, and early heading germplasm. High-throughput phenomics empowered by ML would be of great value to uncover the association with other agronomic traits not yet considered in the previous genetic studies on rust and FHB resistance. Exotic germplasm and landraces hold promise for improving FHB and rust resistance in wheat. Availability of skim sequencing at reasonable cost has made discovering structural variation across various wheat gene pools possible. Skim sequencing of a large number of exotic materials facilitate enhancing the diversity within wheat breeding gene pool.

All in all, we expect GS to be intensively applied in wheat breeding programs given its numerous advantages such as improving selection gain, reducing the need for labor-intensive and costly phenotyping at disease nurseries and accelerating the utilization of genetic variation. The availability and predictability of GS for wheat breeding could be enhanced by ML empowered high-throughput and precise phenotyping, the costeffective application of "omics" for improving the GS predictability, and the availability of endophenotypes such as transcriptome and metabolome data in effort to better model epistatic and genotype $\times$ environment interaction. Reducing the cost per sample for such endophenotypes is a prerequisite for their integration in GS studies in inbred and hybrid wheat breeding. On the other hand, ML would allow for a more accurate disease diagnosis, while preserving energy and generating consistent/repeatable data. However, dataset limitations (number and variety of samples) hamper the development of truly efficient platforms for plant disease classification. Fortunately, some efforts towards building and sharing more representative publicly available databases are underway. Thus, future studies could focus on 
improving across-cycle GS predictability through integrating modern technologies and big data sciences.

\section{CONFLICTS OF INTEREST}

The authors declare that they have no conflicts of interest.

\section{FUNDING}

We are grateful for funding from the Canadian Triticum Applied Genomics research project (CTAG2) funded by Genome Canada, Genome Prairie, the Western Grains Research Foundation, Saskatchewan Ministry of Agriculture, Saskatchewan Wheat Development Commission, Alberta Wheat Commission, Viterra and Manitoba Wheat and Barley Growers Association.

\section{ACKNOWLEDGMENTS}

The authors express their appreciation to anonymous reviewers for their valuable suggestions to improve the manuscript.

\section{REFERENCES}

1. FAO. The future of food and agriculture-Alternative pathways to 2050. Rome (Italy): FAO; 2018. p. 224.

2. Hickey LT, Hafeez AN, Robinson H, Jackson SA, Leal-Bertioli SCM, Tester M, et al. Breeding crops to feed 10 billion. Nat Biotechnol. 2019;37(7):744-54.

3. Gautam HR, Bhardwaj ML, Kumar R. Climate change and its impact on plant diseases. Curr Sci. 2013;105(12):1685-91.

4. FAOSTAT. FAOSTAT Data. Available from: http://wwwfaoorg/faostat/en/\#data/QC 2019. Accessed 26 Apr 2020.

5. Chen XM. Epidemiology and control of stripe rust [Puccinia striiformis f. sp. tritici] on wheat. Can J Plant Pathol. 2005;27(3):314-37.

6. Ellis JG, Lagudah ES, Spielmeyer W, Dodds PN. The past, present and future of breeding rust resistant wheat. Front Plant Sci. 2014;5:641.

7. Huerta-Espino J, Singh RP, Roelfs AP. Rusts fungi of wheat. In: Misra JK, Tewari JP, Deshmukh SK, Vágvölgyi C, editors. Fungi From Different Substrates. Boca Raton (FL, US): CRC Press; 2014. p. 217-59.

8. Hulbert S, Pumphrey M. A time for more booms and fewer busts? Unraveling cereal-rust interactions. Mol Plant Microbe Interact. 2014;27(3):207-14.

9. Kolmer JA. Tracking wheat rust on a continental scale. Curr Opin Plant Biol. 2005;8(4):441-9.

10. McIntosh RA, Wellings CR, Park RF. Wheat Rusts: An Atlas of Resistance Genes. Melbourne (Australia): CSIRO Publishing; 1995.

11. Murray GM, Brennan JP. Estimating disease losses to the Australian wheat industry. Australas Plant Pathol. 2009;38(6):558-70.

12. Stakman EC, Harrar JG. Principles of plant pathology. New York (US): Ronald Press; 1957. 
13. Wicki W, Winzeler M, Schmid JE, Stamp P, Messmer M. Inheritance of resistance to leaf and glume blotch caused by Septoria nodorum Berk. in winter wheat. Theor Appl Genet. 1999;99(7):1265-72.

14. Dexter J, Clear R, Preston K. Fusarium head blight: effect on the milling and baking of some Canadian wheats. Cereal Chem. 1996;73:695-701.

15. Roelfs AP, Singh RP, Saari EE. Rust Diseases of Wheat: Concepts and Methods of Disease Management. Mexico (Mexico): CIMMYT; 1992.

16. Huerta-Espino J, Singh RP, Germán S, McCallum BD, Park RF, Chen WQ, et al. Global status of wheat leaf rust caused by Puccinia triticina. Euphytica. 2011;179(1):143-60.

17. McCallum BD, Hiebert CW, Cloutier S, Bakkeren G, Rosa SB, Humphreys DG, et al. A review of wheat leaf rust research and the development of resistant cultivars in Canada. Can J Plant Pathol. 2016;38(1):1-18.

18. Figueroa M, Hammond-Kosack KE, Solomon PS. A review of wheat diseasesa field perspective. Mol Plant Pathol. 2018;19(6):1523-36.

19. Pretorius ZA, Singh RP, Wagoire WW, Payne TS. Detection of virulence to wheat stem rust resistance gene Sr31 in Puccinia graminis. f. sp. tritici in Uganda. Plant Dis. 2000;84:203.

20. Singh RP, Hodson DP, Jin Y, Lagudah ES, Ayliffe MA, Bhavani S, et al. Emergence and spread of new races of wheat stem rust fungus: Continued threat to food security and prospects of genetic control. Phytopathology. 2015;105(7):872-84.

21. Singh RP, Hodson DP, Huerta-Espino J, Jin Y, Njau P, Wanyera R, et al. Will stem rust destroy the world's wheat crop? In: Volume 98, Advances in Agronomy. Cambridge (MA, US): Academic Press; 2008. p. 271-309.

22. Milus EA, Kristensen K, Hovmøller MS. Evidence for increased aggressiveness in a recent widespread strain of Puccinia striiformis $\mathrm{f}$. sp. tritici causing stripe rust of wheat. Phytopathology. 2009;99(1):89-94.

23. Buerstmayr H, Ban T, Anderson JA. QTL mapping and marker-assisted selection for Fusarium head blight resistance in wheat: a review. Plant Breed. 2009;128(1):1-26.

24. Haile JK, N'Diaye A, Walkowiak S, Nilsen KT, Clarke JM, Kutcher HR, et al. Fusarium head blight in durum wheat: Recent status, breeding directions, and future research prospects. Phytopathology. 2019;109(10):1664-75.

25. Liu S, Hall MD, Griffey CA, McKendry AL. Meta-analysis of QTL associated with Fusarium head blight resistance in wheat. Crop Sci. 2009;49(6):1955-68.

26. Su Z, Bernardo A, Tian B, Chen H, Wang S, Ma H, et al. A deletion mutation in TaHRC confers Fhb1 resistance to Fusarium head blight in wheat. Nat Genet. 2019;51(7):1099-105.

27. Wang H, Sun S, Ge W, Zhao L, Hou B, Wang K, et al. Horizontal gene transfer of Fhb7 from fungus underlies Fusarium head blight resistance in wheat. Science. 2020;368(6493):eaba5435.

28. Pumphrey M, Bernardo R, Anderson JA. Validating the QTL for Fusarium head blight resistance in near-isogenic wheat lines developed from breeding populations. Crop Sci. 2007;47:200-6. 
29. Bernardo AN, Ma H, Zhang D, Bai G. Single nucleotide polymorphism in wheat chromosome region harboring Fhb1 for Fusarium head blight resistance. Mol Breed. 2012;29(2):477-88.

30. Brar GS, Pozniak CJ, Kutcher HR, Hucl PJ. Evaluation of Fusarium head blight resistance genes Fhb1, Fhb2, and Fhb5 introgressed into elite Canadian hard red spring wheats: effect on agronomic and end-use quality traits and implications for breeding. Mol Breed. 2019;39(3):44.

31. Bai GH, Shaner G, Ohm H. Inheritance of resistance to Fusarium graminearum in wheat. Theor Appl Genet. 2000;100(1):1-8.

32. Buerstmayr M, Huber K, Heckmann J, Steiner B, Nelson JC, Buerstmayr H. Mapping of QTL for Fusarium head blight resistance and morphological and developmental traits in three backcross populations derived from Triticum dicoccum × Triticum durum. Theor Appl Genet. 2012;125(8):1751-65.

33. Miedaner T, Longin CFH. Genetic variation for resistance to Fusarium head blight in winter durum material. Crop Pasture Sci. 2014;65(1):46-51.

34. Sari E, Berraies S, Knox RE, Singh AK, Ruan Y, Cuthbert RD, et al. High density genetic mapping of Fusarium head blight resistance QTL in tetraploid wheat. PLoS One. 2018;13(10):e0204362.

35. Sari E, Knox RE, Ruan Y, Henriquez MA, Kumar S, Burt AJ, et al. Historic recombination in a durum wheat breeding panel enables high-resolution mapping of Fusarium head blight resistance quantitative trait loci. Sci Rep. 2020;10(1):7567.

36. Miedaner T, Korzun V. Marker-Assisted Selection for Disease Resistance in Wheat and Barley Breeding. Phytopathology. 2012;102:560-6. http://dx.doi.org/10.1094/PHYTO-05-11-0157

37. Bentley AR, Scutari M, Gosman N, Faure S, Bedford F, Howell P, et al. Applying association mapping and genomic selection to the dissection of key traits in elite European wheat. Theor Appl Genet. 2014;127(12):2619-33.

38. Dwivedi SL, Scheben A, Edwards D, Spillane C, Ortiz R. Assessing and exploiting functional diversity in germplasm pools to enhance abiotic stress adaptation and yield in cereals and food legumes. Front Plant Sci. 2017;8:1461.

39. Jannink J-L, Lorenz AJ, Iwata H. Genomic selection in plant breeding: from theory to practice. Brief Funct Genom. 2010;9(2):166-77.

40. Bernardo R. Bandwagons I, too, have known. Theor Appl Genet. 2016;129(12):2323-32.

41. Xu Y, Li P, Zou C, Lu Y, Xie C, Zhang X, et al. Enhancing genetic gain in the era of molecular breeding. J Exp Bot. 2017;68(11):2641-66.

42. Meuwissen TH, Hayes BJ, Goddard ME. Prediction of total genetic value using genome-wide dense marker maps. Genetics. 2001;157(4):1819-29.

43. Bernardo R, Yu J. Prospects for genomewide selection for quantitative traits in maize. Crop Sci. 2007;47(3):1082-90.

44. Cerrudo D, Cao S, Yuan Y, Martinez C, Suarez EA, Babu R, et al. Genomic selection outperforms marker assisted selection for grain yield and physiological traits in a maize doubled haploid population across water treatments. Front Plant Sci. 2018;9:366. 
45. Guo Z, Tucker DM, Wang D, Basten CJ, Ersoz E, Briggs WH, et al. Accuracy of across-environment genome-wide prediction in maize nested association mapping populations. G3 (Bethesda). 2013;3(2):263-72.

46. Heffner EL, Lorenz AJ, Jannink J-L, Sorrells ME. Plant breeding with genomic Selection: Gain per unit time and cost. Crop Sci. 2010;50(5):1681-90.

47. Mayor PJ, Bernardo R. Genomewide selection and marker-assisted recurrent selection in doubled haploid versus F2 populations. Crop Sci. 2009;49(5):171925.

48. Arruda M, Brown P, Lipka A, Krill A, Thurber C, Kolb F. Genomic selection for predicting Fusarium head blight resistance in a wheat breeding program. Plant Genome. 2015;8:1-12.

49. Castro Aviles A. Identification of quantitative trait loci (QTLs) for resistance to Fusarium head blight (FHB) in wheat variety AGS 2060 and evaluation of the effect of Fhb1 resistance gene on FHB reaction in a Louisiana wheat breeding population [Doctoral Dissertation]. Baton Rouge (LA, US): Louisiana State University (LSU); 2019.

50. Longin CF, Mi X, Wurschum T. Genomic selection in wheat: optimum allocation of test resources and comparison of breeding strategies for line and hybrid breeding. Theor Appl Genet. 2015;128(7):1297-306.

51. Bassi FM, Bentley AR, Charmet G, Ortiz R, Crossa J. Breeding schemes for the implementation of genomic selection in wheat (Triticum spp.). Plant Sci. 2016;242:23-36.

52. Battenfield SD, Guzmán C, Gaynor RC, Singh RP, Peña RJ, Dreisigacker S, et al. Genomic selection for processing and end-use quality traits in the CIMMYT spring bread wheat breeding program. Plant Genome. 2016;9:1-12.

53. Haile JK, N'Diaye A, Clarke F, Clarke J, Knox R, Rutkoski J, et al. Genomic selection for grain yield and quality traits in durum wheat. Mol Breed. 2018;38(6):75.

54. Heffner EL, Sorrells ME, Jannink J-L. Genomic selection for crop improvement. Crop Sci. 2009;49(1):1-12.

55. Ornella L, Singh S, Perez P, Burgueño J, Singh R, Tapia E, et al. Genomic prediction of genetic values for resistance to wheat rusts. Plant Genome. 2012;5(3):136-48.

56. Rutkoski J, Poland J, Mondal S, Autrique E, Pérez LG, Crossa J, et al. Canopy temperature and vegetation indices from high-throughput phenotyping improve accuracy of pedigree and genomic selection for grain yield in wheat. G3 (Bethesda). 2016;6(9):2799-808.

57. Sallam A, Smith K. Genomic selection performs similarly to phenotypic selection in barley. Crop Sci. 2016;56:2871-81.

58. Sorrells ME. Genomic selection in plants: Empirical results and implications for wheat breeding. In: Ogihara Y, Takumi S, Handa H, editors. Advances in Wheat Genetics: From Genome to Field. Tokyo (Japan): Springer Japan; 2015. p. 401-9.

59. Rutkoski J, Heffner E, Sorrells M. Genomic selection for durable stem rust resistance in wheat. Euphytica. 2011;179:161-73. 
60. Poland J, Rutkoski J. Advances and challenges in genomic selection for disease resistance. Annu Rev Phytopathol. 2016;54:79-98.

61. Singh RP, Huerta-Espino J, Bhavani S, Herrera-Foessel SA, Singh D, Singh PK, et al. Race non-specific resistance to rust diseases in CIMMYT spring wheats. Euphytica. 2011;179(1):175-86.

62. Parlevliet JE. Durability of resistance against fungal, bacterial and viral pathogens; present situation. Euphytica. 2002;124(2):147-56.

63. Singh R, Huerta-Espino J, William HM. Genetics and breeding for durable resistance to leaf and stripe rust of wheat. Turkish J Agric For. 2005;29:121-7.

64. Juliana P, Singh RP, Singh PK, Crossa J, Huerta-Espino J, Lan C, et al. Genomic and pedigree-based prediction for leaf, stem, and stripe rust resistance in wheat. Theor Appl Genet. 2017;130(7):1415-30.

65. Shamshad M, Sharma A. The usage of genomic selection strategy in plant breeding. In: Next Generation Plant Breeding. London (UK): IntechOpen; 2018. p. 93-109.

66. Crossa J, Campos Gdl, Pérez P, Gianola D, Burgueño J, Araus JL, et al. Prediction of genetic values of quantitative traits in plant breeding using pedigree and molecular markers. Genetics. 2010;186(2):713-24.

67. Burgueño J, de los Campos G, Weigel K, Crossa J. Genomic prediction of breeding values when modeling genotype $\times$ environment interaction using pedigree and dense molecular markers. Crop Sci. 2012;52(2):707-19.

68. Spindel JE, Begum H, Akdemir D, Collard B, Redoña E, Jannink JL, et al. Genome-wide prediction models that incorporate de novo GWAS are a powerful new tool for tropical rice improvement. Heredity. 2016;116(4):395408.

69. Daetwyler HD, Bansal U, Bariana H, Hayden M, Hayes B. Genomic prediction for rust resistance in diverse wheat landraces. Theor Appl Genet. 2014;127:1795-803.

70. Rutkoski J, Poland J, Singh R, Huerta-Espino J, Bhavani S, Barbier H, et al. Genomic selection for quantitative adult plant stem rust resistance in wheat. Plant Genome. 2014;7:1-10.

71. Tomar V, Singh R, Poland J, Singh D, Joshi A, Singh P, et al. Genome-wide association study and Genomic Prediction of spot blotch disease in wheat (Triticum aestivum L.) using genotyping by sequencing. Research Square PPR125490 [Priprint]. [Posted 06 Feb 2020]. doi: 10.21203/rs.2.22818/v1

72. Odilbekov F, Armoniené R, Koc A, Svensson J, Chawade A. GWAS-assisted genomic prediction to predict resistance to Septoria Tritici Blotch in Nordic winter wheat at seedling stage. Front Genet. 2019;10:1224.

73. Sehgal D, Rosyara U, Mondal S, Singh R, Poland J, Dreisigacker S. Incorporating genome-wide association mapping results into genomic prediction models for grain yield and yield stability in CIMMYT spring bread wheat. Front Plant Sci. 2020;11:197.

74. Arruda MP, Lipka AE, Brown PJ, Krill AM, Thurber C, Brown-Guedira G, et al. Comparing genomic selection and marker-assisted selection for Fusarium head blight resistance in wheat (Triticum aestivum L.). Mol Breed. 2016;36(7):84. 
75. Crossa J, Jarquín D, Franco J, Pérez-Rodríguez P, Burgueño J, Saint-Pierre C, et al. Genomic prediction of gene bank wheat landraces. G3 (Bethesda). 2016;6(7):1819-34.

76. Muleta KT, Bulli P, Zhang Z, Chen X, Pumphrey M. Unlocking diversity in germplasm collections via genomic selection: A case study based on quantitative adult plant resistance to stripe rust in spring wheat. Plant Genome. 2017;10(3):1-15.

77. Olatoye MO, Clark LV, Wang J, Yang X, Yamada T, Sacks EJ, et al. Evaluation of genomic selection and marker-assisted selection in Miscanthus and energycane. Mol Breed. 2019;39(12):171.

78. Ornella L, González-Camacho JM, Dreisigacker S, Crossa J. Applications of genomic selection in breeding wheat for rust resistance. Methods Mol Biol. 2017;1659:173-82.

79. Pilet-Nayel M-L, Moury B, Caffier V, Montarry J, Kerlan M-C, Fournet S, et al. Quantitative resistance to plant pathogens in pyramiding strategies for durable crop protection. Front Plant Sci. 2017;8:1838.

80. Quenouille J, Montarry J, Palloix A, Moury B. Farther, slower, stronger: how the plant genetic background protects a major resistance gene from breakdown. Mol Plant Pathol. 2013;14(2):109-18.

81. Rutkoski J, Singh RP, Huerta-Espino J, Bhavani S, Poland J, Jannink JL, et al. Efficient use of historical data for genomic selection: A case study of stem rust resistance in wheat. Plant Genome. 2015;8(1):1-10. https://doi.org/10.3835/plantgenome2014.09.0046

82. Sneller C, Guttieri M, Paul P, Costa J, Jackwood R. Variation for resistance to kernel infection and toxin accumulation in winter wheat infected with Fusarium graminearum. Phytopathology. 2012;102(3):306-14.

83. Moreno-Amores J, Michel S, Miedaner T, Longin CFH, Buerstmayr H. Genomic predictions for Fusarium head blight resistance in a diverse durum wheat panel: An effective incorporation of plant height and heading date as covariates. Euphytica. 2020;216(2):22.

84. Endelman JB. Ridge Regression and other kernels for genomic selection with R package rrBLUP. Plant Genome. 2011;4(3):250-5.

85. Resende MFR, Muñoz P, Resende MDV, Garrick DJ, Fernando RL, Davis JM, et al. Accuracy of genomic selection methods in a standard data set of Loblolly Pine (Pinus taeda L.). Genetics. 2012;190(4):1503-10.

86. Tibshirani R. Regression shrinkage and selection via the lasso. J R Stat Soc Series B Stat Methodol. 1996;58(1):267-88.

87. Zou H, Hastie T. Regularization and variable selection via the elastic net. J R Stat Soc Series B Stat Methodol. 2005;67(2):301-20.

88. Rutkoski J, Benson J, Jia Y, Brown-Guedira G, Jannink J-L, Sorrells M. Evaluation of genomic prediction methods for Fusarium head blight resistance in wheat. Plant Genome. 2012;5:51-61.

89. Clark SA, van der Werf J. Genomic best linear unbiased prediction (gBLUP) for the estimation of genomic breeding values. Methods Mol Biol. 2013;1019:321-30. 
90. Schulthess AW, Zhao Y, Longin CFH, Reif JC. Advantages and limitations of multiple-trait genomic prediction for Fusarium head blight severity in hybrid wheat (Triticum aestivum L.). Theor Appl Genet. 2018;131(3):685-701.

91. Steiner B, Michel S, Maccaferri M, Lemmens M, Tuberosa R, Buerstmayr H. Exploring and exploiting the genetic variation of Fusarium head blight resistance for genomic-assisted breeding in the elite durum wheat gene pool. Theor Appl Genet. 2019;132(4):969-88.

92. Miedaner T, Sieber A-N, Desaint H, Buerstmayr H, Longin CFH, Würschum T. The potential of genomic-assisted breeding to improve Fusarium head blight resistance in winter durum wheat. Plant Breed. 2017;136(5):610-9.

93. Buerstmayr H, Stierschneider M, Steiner B, Lemmens M, Griesser M, Nevo E, et al. Variation for resistance to head blight caused by Fusarium graminearum in wild emmer (Triticum dicoccoides) originating from Israel. Euphytica. 2003;130(1):17-23.

94. Buerstmayr M, Buerstmayr H. The Semidwarfing alleles Rht-D1b and Rht-B1b show marked differences in their associations with anther-retention in wheat heads and with Fusarium head blight susceptibility. Phytopathology. 2016;106(12):1544-52.

95. He X, Singh PK, Dreisigacker S, Singh S, Lillemo M, Duveiller E. Dwarfing genes Rht-B1b and Rht-D1b are associated with both type I FHB susceptibility and low anther extrusion in two bread wheat populations. PLoS One. 2016;11(9):e0162499.

96. Herter CP, Ebmeyer E, Kollers S, Korzun V, Würschum T, Miedaner T. Accuracy of within- and among-family genomic prediction for Fusarium head blight and Septoria tritici blotch in winter wheat. Theor Appl Genet. 2019;132(4):1121-35.

97. Liu Y, Salsman E, Fiedler JD, Hegstad JB, Green A, Mergoum M, et al. Genetic mapping and prediction analysis of FHB resistance in a hard red spring wheat breeding population. Front Plant Sci. 2019;10:1007.

98. Dong H, Wang R, Yuan Y, Anderson J, Pumphrey M, Zhang Z, et al. Evaluation of the potential for genomic selection to improve spring wheat resistance to Fusarium head blight in the Pacific Northwest. Front Plant Sci. 2018;9:911.

99. Jia Y, Jannink J-L. Multiple-trait genomic selection methods increase genetic value prediction accuracy. Genetics. 2012;192(4):1513-22.

100. Qiu R, Yang C, Moghimi A, Zhang M, Steffenson JB, Hirsch DC. Detection of Fusarium head blight in wheat using a deep neural network and color imaging. Remote Sens. 2019;11(22):2658.

101. Deery D, Jimenez-Berni J, Jones H, Sirault X, Furbank R. Proximal remote sensing buggies and potential applications for field-based phenotyping. Agronomy. 2014;4(3):349-79.

102. White JW, Andrade-Sanchez P, Gore MA, Bronson KF, Coffelt TA, Conley MM, et al. Field-based phenomics for plant genetics research. Field Crops Res. 2012;133:101-12.

103. Xu C, Jackson SA. Machine learning and complex biological data. Genome Biol. 2019;20(1):76. 
104. Zitnik M, Nguyen F, Wang B, Leskovec J, Goldenberg A, Hoffman MM. Machine learning for integrating data in biology and medicine: Principles, practice, and opportunities. Inf Fusion. 2019;50:71-91.

105. $\mathrm{Hu} \mathrm{H}$, Scheben A, Edwards D. Advances in integrating genomics and bioinformatics in the plant breeding pipeline. Agriculture. 2018;8(6):75.

106. Takahashi K, Kim K, Ogata T, Sugano S. Tool-body assimilation model considering grasping motion through deep learning. Rob Auton Syst. 2017;91:115-27.

107. Olson RS, Cava WL, Mustahsan Z, Varik A, Moore JH. Data-driven advice for applying machine learning to bioinformatics problems. Pac Symp Biocomput. 2018;23:192-203.

108. Costello Z, Martin HG. A machine learning approach to predict metabolic pathway dynamics from time-series multiomics data. NPJ Syst Biol Appl. 2018;4(1):19.

109. Doan M, Carpenter AE. Leveraging machine vision in cell-based diagnostics to do more with less. Nat Mater. 2019;18(5):414-8.

110. Jurmeister P, Bockmayr M, Seegerer P, Bockmayr T, Treue D, Montavon G, et al. Machine learning analysis of DNA methylation profiles distinguishes primary lung squamous cell carcinomas from head and neck metastases. Sci Transl Med. 2019;11(509):eaaw8513.

111. Rhee J, Im J. Meteorological drought forecasting for ungauged areas based on machine learning: Using long-range climate forecast and remote sensing data. Agric For Meteorol. 2017;237-238:105-22.

112. Fang K, Shen C, Kifer D, Yang X. Prolongation of SMAP to spatiotemporally seamless coverage of continental U.S. using a deep learning neural network. Geophys Res Lett. 2017;44(21):11,030-11,9.

113. Mejía-Guerra MK, Buckler ES. A k-mer grammar analysis to uncover maize regulatory architecture. BMC Plant Biol. 2019;19(1):103.

114. Washburn JD, Mejia-Guerra MK, Ramstein G, Kremling KA, Valluru R, Buckler ES, et al. Evolutionarily informed deep learning methods for predicting relative transcript abundance from DNA sequence. Proc Natl Acad Sci U S A. 2019;116(12):5542-9.

115. Ghosal S, Blystone D, Singh AK, Ganapathysubramanian B, Singh A, Sarkar S. An explainable deep machine vision framework for plant stress phenotyping. Proc Natl Acad Sci U S A. 2018;115(18):4613-8.

116. Jaewon C, Trung TT, Thien TLH, Geon-Soo P, Dang CV, Jongwook K. A Nutrient deficiency prediction method using deep learning on development of tomato fruits. In: 2018 International Conference on Fuzzy Theory and Its Applications (iFUZZY); 2018 Nov 14-7; Daegu, South Korea.

117. Mishra S, Mishra D, Santra GH. Applications of machine learning techniques in agricultural crop production: A review paper. Indian J Sci Technol. 2016;9(38):1-14.

118. Jeong JH, Resop JP, Mueller ND, Fleisher DH, Yun K, Butler EE, et al. Random forests for global and regional crop yield predictions. PLoS One. 2016;11(6):e0156571. 
119. Pantazi XE, Moshou D, Alexandridis T, Whetton RL, Mouazen AM. Wheat yield prediction using machine learning and advanced sensing techniques. Comput Electron Agric. 2016;121(C):57-65.

120. Aghighi H, Azadbakht M, Ashourloo D, Shahrabi HS, Radiom S. Machine learning regression techniques for the silage maize yield prediction using time-series images of Landsat 8 OLI. IEEE J Sel Top Appl Earth Obs Remote Sens. 2018;11(12):4563-77.

121. Jin X, Jie L, Wang S, Qi HJ, Li SW. Classifying wheat hyperspectral pixels of healthy heads and Fusarium head blight disease using a deep neural network in the wild field. Remote Sens. 2018;10(3):395.

122. González-Camacho JM, Ornella L, Pérez-Rodríguez P, Gianola D, Dreisigacker $\mathrm{S}$, Crossa J. Applications of machine learning methods to genomic selection in breeding wheat for rust resistance. Plant Genome. 2018;11:170104.

123. Barbedo JGA. Factors influencing the use of deep learning for plant disease recognition. Biosyst Eng. 2018;172:84-91.

124. Arnal Barbedo JG. Plant disease identification from individual lesions and spots using deep learning. Biosyst Eng. 2019;180:96-107.

125. Ferentinos KP. Deep learning models for plant disease detection and diagnosis. Comput Electron Agric. 2018;145:311-8.

126. Li B, Zhang N, Wang Y-G, George AW, Reverter A, Li Y. Genomic prediction of breeding values using a subset of SNPs identified by three machine learning methods. Front Genet. 2018;9:237.

127. Libbrecht MW, Noble WS. Machine learning applications in genetics and genomics. Nat Rev Genet. 2015;16(6):321-32.

128. Rasheed A, Hao Y, Xia X, Khan A, Xu Y, Varshney RK, et al. Crop breeding chips and genotyping platforms: progress, challenges, and perspectives. Mol Plant. 2017;10(8):1047-64.

129. Appels R, Eversole K, Stein N, Feuillet C, Keller B, Rogers J, et al. Shifting the limits in wheat research and breeding using a fully annotated reference genome. Science. 2018;361(6403):eaar7191.

130. Maccaferri M, Harris NS, Twardziok SO, Pasam RK, Gundlach H, Spannagl M, et al. Durum wheat genome highlights past domestication signatures and future improvement targets. Nat Genet. 2019;51(5):885-95.

131. Cavanagh CR, Chao S, Wang S, Huang BE, Stephen S, Kiani S, et al. Genomewide comparative diversity uncovers multiple targets of selection for improvement in hexaploid wheat landraces and cultivars. Proc Natl Acad Sci U S A. 2013;110(20):8057-62.

132. Wang S, Wong D, Forrest K, Allen A, Chao S, Huang BE, et al. Characterization of polyploid wheat genomic diversity using a high-density 90,000 single nucleotide polymorphism array. Plant Biotechnol J. 2014;12(6):787-96.

133. Winfield MO, Allen AM, Burridge AJ, Barker GL, Benbow HR, Wilkinson PA, et al. High-density SNP genotyping array for hexaploid wheat and its secondary and tertiary gene pool. Plant Biotechnol J. 2016;14(5):1195-206.

134. Uauy C, Wulff BBH, Dubcovsky J. Combining traditional mutagenesis with new high-throughput sequencing and genome editing to reveal hidden variation in polyploid wheat. Annu Rev Genet. 2017;51(1):435-54. 
135. Ramirez-Gonzalez RH, Segovia V, Bird N, Fenwick P, Holdgate S, Berry S, et al. RNA-Seq bulked segregant analysis enables the identification of highresolution genetic markers for breeding in hexaploid wheat. Plant Biotechnol J. 2015;13(5):613-24.

136. He F, Pasam R, Shi F, Kant S, Keeble-Gagnere G, Kay P, et al. Exome sequencing highlights the role of wild-relative introgression in shaping the adaptive landscape of the wheat genome. Nat Genet. 2019;51(5):896-904.

137. Poland J, Endelman J, Dawson J, Rutkoski J, Wu S, Manes Y, et al. Genomic Selection in Wheat Breeding using Genotyping-by-Sequencing. Plant Genome. 2012;5(3):103-13.

138. Jupe F, Witek K, Verweij W, Sliwka J, Pritchard L, Etherington GJ, et al. Resistance gene enrichment sequencing (RenSeq) enables reannotation of the NB-LRR gene family from sequenced plant genomes and rapid mapping of resistance loci in segregating populations. Plant J. 2013;76(3):530-44.

139. Borrill P, Harrington SA, Uauy C. Applying the latest advances in genomics and phenomics for trait discovery in polyploid wheat. The Plant J. 2019;97(1):56-72.

140. Heffner E, Jannink J-L, Sorrells M. Genomic selection accuracy using multifamily prediction models in a wheat breeding program. Plant Genome J. 2011;4:65.

141. Norman A, Taylor J, Edwards J, Kuchel H. Optimising genomic selection in wheat: Effect of marker density, population size and population structure on prediction accuracy. G3 (Bethesda). 2018;8(9):2889-99.

142. Hickey JM, Dreisigacker S, Crossa J, Hearne S, Babu R, Prasanna BM, et al. Evaluation of genomic selection training population designs and genotyping strategies in plant breeding programs using simulation. Crop Sci. 2014;54(4):1476-88.

143. N'Diaye A, Haile JK, Cory AT, Clarke FR, Clarke JM, Knox RE, et al. Single marker and haplotype-based association analysis of semolina and pasta colour in elite durum wheat breeding lines using a high-density consensus map. PLoS One. 2017;12(1):e0170941.

144. Jordan KW, Wang S, Lun Y, Gardiner L-J, MacLachlan R, Hucl P, et al. A haplotype map of allohexaploid wheat reveals distinct patterns of selection on homoeologous genomes. Genome Biol. 2015;16:48.

145. Schrag TA, Westhues M, Schipprack W, Seifert F, Thiemann A, Scholten S, et al. Beyond genomic prediction: combining different types of omics data can improve prediction of hybrid performance in maize. Genetics. 2018;208(4):1373-85.

146. Guo Z, Magwire MM, Basten CJ, Xu Z, Wang D. Evaluation of the utility of gene expression and metabolic information for genomic prediction in maize. Theor Appl Genet. 2016;129(12):2413-27.

147. Westhues M, Schrag TA, Heuer C, Thaller G, Utz HF, Schipprack W, et al. Omics-based hybrid prediction in maize. Theor Appl Genet. 2017;130(9):192739. 
148. Gamazon ER, Wheeler HE, Shah KP, Mozaffari SV, Aquino-Michaels K, Carroll RJ, et al. A gene-based association method for mapping traits using reference transcriptome data. Nat Genet. 2015;47(9):1091-8.

149. Sholder G, Lanz TA, Moccia R, Quan J, Aparicio-Prat E, Stanton R, et al. 3'Poolseq: an optimized cost-efficient and scalable method of whole-transcriptome gene expression profiling. BMC Genomics. 2020;21(1):64.

150. Uzbas F, Opperer F, Sönmezer C, Shaposhnikov D, Sass S, Krendl C, et al. BARTSeq: cost-effective massively parallelized targeted sequencing for genomics, transcriptomics, and single-cell analysis. Genome Biol. 2019;20(1):155.

151. Gupta PK, Balyan HS, Gahlaut V, Saripalli G, Pal B, Basnet BR, et al. Hybrid wheat: past, present and future. Theor Appl Genet. 2019;132(9):2463-83.

How to cite this article:

Haile JK, N’Diaye A, Sari E, Walkowiak S, Rutkoski J, Kutcher RK, Pozniak CJ. Potential of Genomic Selection and Integrating “Omics” Data for Disease Evaluation in Wheat. Crop Breed Genet Genom. 2020;2(4):e200016. https://doi.org/10.20900/cbgg20200016 